\title{
Production of biodiesel by enzymatic transesterification of non-edible Salvadora persica (Pilu) oil and crude coconut oil in a solvent-free system
}

\author{
Azeem Abdul Aziz Budhwani ${ }^{1,2^{*}}$, Ayesha Maqbool ${ }^{1}$, Tanveer Hussain ${ }^{1}$ and Muhammad Noman Syed ${ }^{2}$
}

\begin{abstract}
Background: It is becoming imperative to develop renewable fuels such as biodiesel which are sustainable and environmentally friendly. Exploiting non-edible oils is more necessary to reduce dependency of edible oils for biodiesel production. The current study investigated biodiesel production from non-edible Salvadora persica seed oil (SPSO) and crude coconut oil (CCO) by Burkholderia cepacia lipase acting as a biocatalyst in a solvent-free system. The biodiesel yield produced from these feedstocks was compared and the effect of ethanol (acyl acceptor) vs. SPSO and CCO in various ratios on biodiesel production was determined.

Results: The presence of medium-chain fatty acids in majority was confirmed for SPSO and CCO while the average molecular weight was calculated as $749.53 \mathrm{~g} / \mathrm{mol}$ and $664.57 \mathrm{~g} / \mathrm{mol}$, respectively. Thin Layer Chromatography indicated ethyl esters in the produced Salvadora and coconut biodiesel samples. Maximum biodiesel yield (around 70\%) was obtained at 1:4 oil-to-ethanol molar ratio from both oils followed by a decline at higher ratios. The gas chromatographic analysis of Salvadora biodiesel at 1:4 molar ratio showed that the yield of individual esters was mostly of medium- and long-chain fatty acids. The analysis of coconut biodiesel at 1:4 molar ratio revealed that it consists mainly of the esters of medium-chain fatty acids. A comparison of estimated properties of biodiesel from both the parent oils with the international standard showed that it meets most of the requirements.

Conclusion: The study paves the way for a green route for biodiesel production and would promote the use of non-edible vegetable oils over edible ones to produce biodiesel. Further, it is a right step to use lipases in biodiesel production as compared to chemical catalysts. Ethanol, which can also be produced from biomass fermentation, can be used as acyl acceptor to produce biodiesel and this makes the process eco-friendly. Moreover, Burkholderia cepacia lipase is a good choice among lipases to get high biodiesel yields successfully from SPSO and CCO at low oil-to-ethanol molar ratios.
\end{abstract}

Keywords: Salvadora persica seed oil, Crude coconut oil, Biodiesel, Thin layer chromatography, Gas chromatography

\section{Introduction}

The current world is in a dilemma as the demand of diminishing reserves of fossil fuels is rising in all sectors of life including industrial processes, power generation, and transport. The increasing demand of fossil

\footnotetext{
${ }^{*}$ Correspondence: azpak7xp@gmail.com

${ }^{1}$ Department of Molecular Biology, Faculty of Science and Technology, Virtual University of Pakistan, Lahore, Pakistan

Full list of author information is available at the end of the article
}

fuels is heightening the environmental concerns such as increasing $\mathrm{CO}_{2}$ and greenhouse gas emissions and global warming (Talebian-Kiakalaieh et al. 2013). Moreover, the prices of fossil fuels are undergoing fluctuations. Given these concerns, it is imperative to develop renewable fuels which are sustainable and environmentally friendly in the future (Sharma and Kar 2015).

One of the alternate and renewable fuel is biodiesel consisting of fatty acid alkyl esters and produced by 
transesterification reaction of plant oils or animal fats (Saifuddin et al. 2016). The biofuel is being used as an alternative to petroleum-based diesel fuel (Sebastian et al. 2016). Biodiesel is usually produced from edible vegetable oil which is problematic as it raises the food vs. fuel crisis. Exploiting non-edible oils is one of the solutions to reduce dependency of edible oils for biodiesel production. The non-edible oils are available in many regions of the world especially wastelands and they can be utilized to eliminate competition with food (Atabani et al. 2012).

Salvadora persica is popularly known as miswak, a teeth-cleaning twig which is made from the tree (Kumar et al. 2012). The plant species belongs to the family Salvadoraceae (Khan and Qaiser 2006). The seeds of S. persica contain $40-45 \%$ oil which consists mainly of lauric $(20 \%)$ and myristic acids (55\%) which can be classified among saturated medium-chain fatty acids. Long-chain fatty acids are found in minor quantities such as palmitic acid (20\%) and oleic acid (5\%). The oil is non-edible as it contains substituted dibenzyl urea (Reddy et al. 2008; Gunstone et al. 2007; Mariod et al. 2009) and is also known as Pilu oil (Kumar et al. 2012). Previously, it was shown that the plant species Salvadora persica has the potential to become an oilseed crop because of the fact that it can be cultivated even in saline and alkaline soils being a facultative halophyte (Reddy et al. 2008).

The coconut tree (Cocos nucifera) is among the most useful and beautiful trees in the tropics. The coconut oil is the dominant product of the coconut (Pham 2016). The oil is broadly used for food and industrial purpose and is rich in saturated fatty acids with low molecular weight (Marina et al. 2009; Shahidi 2006). However, it comes in several types. Among them crude coconut oil is the basic oil processed from copra (dried coconut meat) and is unsuitable for consumption. Further, high-quality copra contains about 65 to $72 \%$ oil (Bureau 2007). Crude coconut oil consists of the majority of triacylglycerols (95\%) (Rahman 2000). The oil is rich in saturated mediumchain fatty acids like caprylic (6.9-9.4\%), capric acid (6.2-7.8\%), lauric acid (45.9-50.3\%), and myristic acid (16.8-19.2\%), whereas long-chain fatty acids are found in smaller amounts such as palmitic acid (7.7-9.7\%), oleic acid (5.4-7.4\%), and linoleic acid (1.3-2.1\%) (Rossell et al. 1985).

Medium-chain fatty acid methyl/ethyl esters of biodiesel are superior to long-chain fatty acid methyl/ethyl esters in most critical parameters (Chen et al. 2012). Thus, we propose here that both Salvadora persica seed oil and crude coconut oil are novel, valuable and potential bioresources to produce biodiesel. The biofuel produced from transesterification by lipase catalyst is preferred over chemical catalyst due to several advantages. Among the choice of lipases, Burkholderia cepacia lipase showed capable results (Jegannathan et al. 2010; Souza et al. 2016). Ethanol is selected as acyl acceptor over methanol as it can be regenerated from biomass and is less toxic (Abdulla and Ravindra 2013). Therefore, the main aim of this study was to compare the yield of biodiesel produced from non-edible Salvadora persica seed oil (SPSO) and crude coconut oil (CCO) by Burkholderia cepacia lipase in a solvent-free system as well as to determine the effect of various molar ratio of ethanol vs. SPSO and CCO on biodiesel production.

\section{Materials and methods}

\section{Chemicals and reagents}

Salvadora persica root oil, SPSO, and CCO were acquired from a local market in Saddar, Karachi. Biocatalyst Amano Lipase PS (30,000 U/g) of Burkholderia cepacia was acquired from Sigma Aldrich and kept at an optimum temperature of $50{ }^{\circ} \mathrm{C}$ and $\mathrm{pH} 7.0$, respectively. Molecular sieves ( $4 \AA$, powder, activated, and -325 mesh particle size and 25 g quantity) were also purchased from Sigma Aldrich.

\section{Gas chromatographic analysis of the oil feedstock and average molecular weight determination}

Analysis of Salvadora persica root oil, SPSO, and CCO was conducted through gas chromatography to determine their fatty acid composition. From the results, the average molecular weights of SPSO and CCO were calculated using the following equations:

$$
\mathrm{MW}_{i}=14.027 C-2.016 d+31.9988,
$$

where MWi is the molecular weight of a single fatty acid ' $i$,' ' $C$ ' is the number of carbon atoms and ' $\mathrm{d}$ ' is the number of double bonds.

Average molecular weight of fatty acids

$$
=\sum f_{i} / \sum\left(f_{i} / \mathrm{MW}_{i}\right) \text {, }
$$

where ' $\mathrm{f}_{\mathrm{i}}$ ' is the weight fraction of a reported fatty acid.

$$
\begin{aligned}
& \text { Average Molecular weight (MW) } \\
& =3 * \text { Average molecular weight of fatty acids } \\
& +38.049 \text {, }
\end{aligned}
$$

where 38.049 is the weight of glycerol backbone (Shrestha and Gerpen 2010).

\section{Rounds and batches of biodiesel production}

The transesterification reactions were carried out using SPSO and ethanol in different ratios under conditions of $50{ }^{\circ} \mathrm{C}$ temperature and $\mathrm{pH} 7.0$ as to find the best one that gives the highest yield. In the next round, $\mathrm{CCO}$ was used, 
and it was reacted with ethanol in different ratios under the same conditions. Both rounds employed the same enzyme. The oils were used without any pre-treatment.

\section{Biodiesel production and purification for each batch}

$0.5 \mathrm{~g}$ of molecular sieves was added in a screw-capped test tube to remove all water molecules that would form during transesterification. Oil $(5.0 \mathrm{~g})$ was taken and mixed with ethanol in 1:4, 1:6, 1:8, 1:10, and 1:12 ratios. Then $50 \mathrm{mg}$ of lipase in free form (1500 U activity) was added to the reaction mixture. After adding the enzyme, the mixture was placed in a shaking water bath. The maximum time for the reaction was $48 \mathrm{~h}$ and the temperature was fixed at $50{ }^{\circ} \mathrm{C}$. After completion of the reaction, the mixture was centrifuged at $5000 \mathrm{rpm}$ for $5 \mathrm{~min}$ to separate biocatalyst, molecular sieves, and glycerol from the produced biodiesel (in this case fatty acid ethyl esters). The supernatant was then transferred into a separating funnel in which equal volumes of distilled water were added. The funnel was closed and then shaken by inverting it many times for separation of the phases. The organic phase, which consisted of fatty acid ethyl esters (biodiesel), was transferred to a container.

\section{Thin layer chromatographic analysis of the produced} biodiesel

For checking the presence of fatty acid ethyl esters, Thin Layer Chromatography (TLC) of the biodiesel samples was performed using Merck SG-60 chromatoplates as stationary phase and a mixture of toluene, chloroform, and acetone $(7: 2: 1 \mathrm{v} / \mathrm{v} / \mathrm{v})$ as the mobile phase (Fontana et al. 2009). Iodine vapors (after placing 5-6 iodine chips in a jar and heating in an oven) were then applied to the plate as a stain for visualization. Images of the stained plates were taken with a camera.

\section{Gas chromatographic analysis of the produced biodiesel}

The biodiesel samples were analyzed by gas chromatography to determine the percentage yield for finding the effect of oil-to-ethanol ratio on biodiesel production and comparing the yield of Salvadora biodiesel and coconut biodiesel.

\section{Estimation of biodiesel properties and comparison with standard}

The properties of Salvadora biodiesel and coconut biodiesel based on fatty acid profiles of SPSO and CCO, respectively, were estimated using BiodieselAnalyzer@ Version 2.2 (available on "http://www.brteam.ir/biodi eselanalyzer") (Talebi et al. 2014) and then compared with ASTM standard of biodiesel (Carvalho et al. 2017).

\section{Results}

Fatty acid profile of Salvadora persica root oil, SPSO, and CCO

With the idea of determining the fatty acid composition of the three oils, fatty acid profile was carried out and the results confirmed the presence of medium-chain fatty acids in majority for the oils that were used for biodiesel production. This is illustrated in Table 1. In case of SPSO, lauric acid and myristic acid made up to $53.88 \%$ of fatty acid composition. Thus, SPSO was used as a feedstock for

Table 1 Fatty acid profile of Salvadora persica oils and CCO (\%)

\begin{tabular}{|c|c|c|c|c|c|c|}
\hline S. no & Fatty acids & Carbon chain & Retention time & $\begin{array}{l}\text { Salvadora persica } \\
\text { seed oil }\end{array}$ & $\begin{array}{l}\text { Salvadora persica } \\
\text { root oil }\end{array}$ & $\begin{array}{l}\text { Crude coconut } \\
\text { oil (Cocos } \\
\text { nucifera) }\end{array}$ \\
\hline 1 & Caprylic acid & 08:0 & 7.4 & $\mathrm{Nd}$ & $\mathrm{Nd}$ & 5.35 \\
\hline 2 & Capric acid & $10: 0$ & 9.9 & $\mathrm{Nd}$ & $\mathrm{Nd}$ & 7.64 \\
\hline 3 & Lauric acid & $12: 0$ & 11.9 & 20.53 & 14.75 & 44.45 \\
\hline 4 & Myristic acid & $14: 0$ & 13.7 & 33.35 & 18.47 & 19.45 \\
\hline 5 & Palmitic acid & $16: 0$ & 15.4 & 27.57 & 35.58 & 10.65 \\
\hline 6 & Oleic acid & $18: 1$ & 17.0 & 9.54 & 16.59 & 7.43 \\
\hline 7 & Linoleic acid & $18: 2$ & 17.3 & $\mathrm{Nd}$ & 1.58 & 0.86 \\
\hline 8 & Arachidic acid & $20: 0$ & 18.3 & 0.57 & 0.45 & 0.24 \\
\hline 9 & Gadolic acid & $20: 1$ & 18.4 & 4.15 & 0.97 & $\mathrm{Nd}$ \\
\hline 10 & Behenic acid & $22: 0$ & 20.0 & 0.67 & 1.45 & $\mathrm{Nd}$ \\
\hline \multirow[t]{2}{*}{11} & Lignoceric acid & $24: 0$ & 22.8 & 0.24 & 0.69 & $\mathrm{Nd}$ \\
\hline & Unidentified & & & 3.38 & 9.47 & 3.93 \\
\hline
\end{tabular}

nd not detected

Gas chromatographic analysis of the oil feedstock: SPSO, Salvadora persica root oil, and CCO. The data are shown as fatty acid methyl ester composition of selected oil samples (\%); nd means that specific fatty acid was not detected 
biodiesel production. In contrast, Salvadora persica root oil had palmitic acid, a long-chain fatty acid in majority (35.58\%). Thus, it was not selected for biodiesel production. The $\mathrm{CCO}$ had lauric acid, a medium-chain fatty acid in majority (44.45\%). Other medium-chain fatty acids detected were caprylic acid (5.35\%), capric acid (7.64\%), and myristic acid (19.45\%) while the total composition of medium-chain fatty acids ranged up to $76.89 \%$. Therefore, CCO was also used in transesterification reactions to produce biodiesel.

\section{Determination of average molecular weight of oils}

The average molecular weight of SPSO was calculated as $749.53 \mathrm{~g} / \mathrm{mol}$ while that of CCO was determined as $664.57 \mathrm{~g} / \mathrm{mol}$ using the respective fatty acid profile and the above equations.

\section{TLC analysis of Salvadora and coconut biodiesel samples} TLC analysis of Salvadora biodiesel samples produced from all batches of SPSO (except for lane 1) showed similar patches which indicates fatty acid ethyl esters were present. In lane 1 (1:4 oil-to-ethanol molar ratio), mixed patches of oil and fatty acid ethyl esters were obtained. TLC analysis of coconut biodiesel samples produced from all batches of $\mathrm{CCO}$ showed similar and light patches obtained which is indicative of the fatty acid ethyl esters produced.
Effect of oil-to-ethanol molar ratio on biodiesel production It was observed by gas chromatographic analysis that esterification of fatty acids is affected by oil-to-ethanol molar ratio as shown in Fig. 1. As the molar ratio was increased, a decline in the yield of fatty acid ethyl esters was detected. The maximum yield of $72 \%$ Salvadora biodiesel was obtained in 1:4 SPSO-to-ethanol molar ratio. The lowest values were obtained in 1:10 and 1:12 molar ratio $(16 \%)$. The maximum yield of $70 \%$ coconut biodiesel was attained in 1:4 CCO-to-ethanol molar ratio. The lowest value was attained in 1:12 ratio (14\%). Other parameters such as temperature, lipase concentration, and incubation period were not altered during experiments with both oils.

\section{A comparison of yield of Salvadora biodiesel and coconut biodiesel}

The gas chromatographic analysis of the Salvadora biodiesel yield obtained from the most productive ratio (1:4 SPSO-to-ethanol molar ratio) showed that the percent yield of the individual esters was mainly of medium and long fatty acids viz. ethyl laurate, ethyl myristate, ethyl palmitate, and ethyl oleate (Fig. 2). Thus, Salvadora biodiesel consisted mainly of the esters of mediumand long-chain fatty acids. In contrast, it was observed by gas chromatographic analysis of coconut biodiesel yield attained from the most productive ratio $(1: 4$

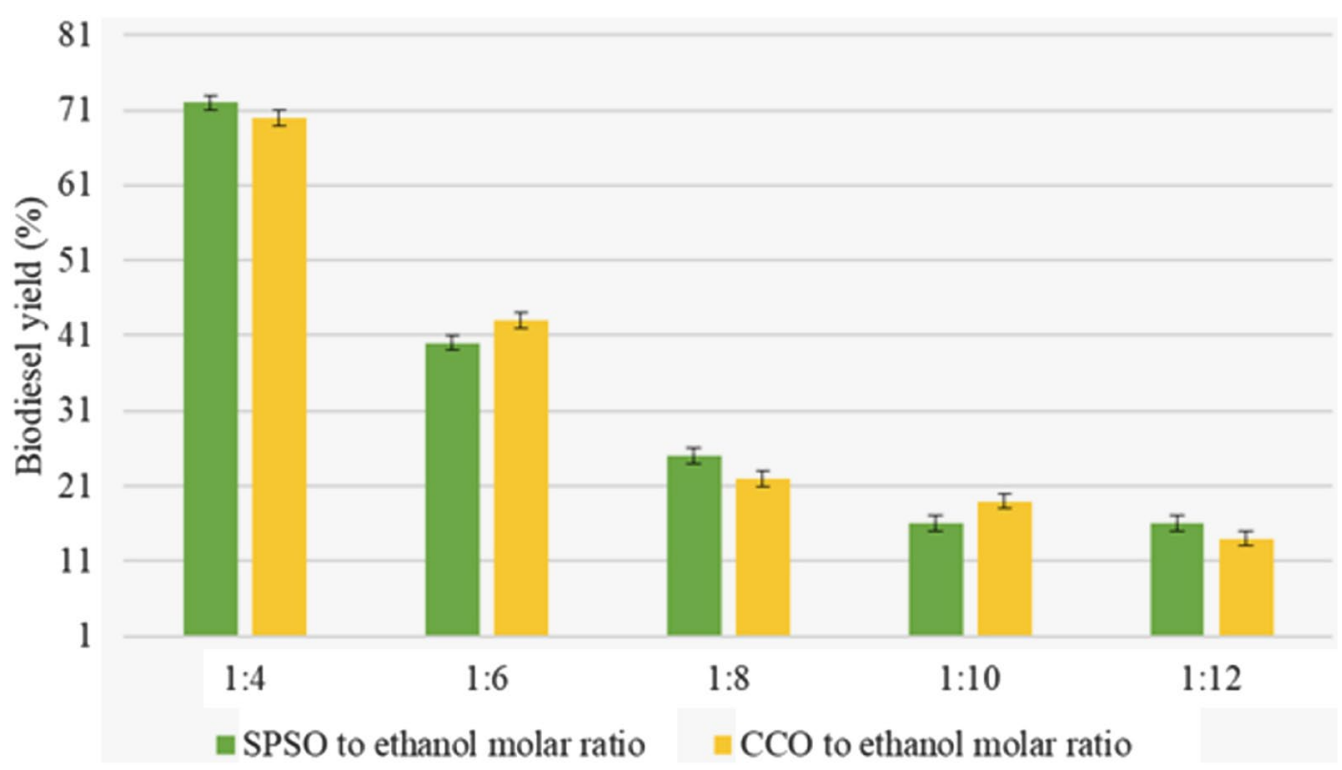

Fig. 1 Effect of oil-to-ethanol molar ratio on biodiesel production. Salvadora and coconut biodiesel samples were analyzed through gas chromatography to determine the oil-to-ethanol molar ratio on biodiesel production. A similar yet declining trend in percent yield was observed in both cases as the molar ratio was increased. In case of Salvadora biodiesel, maximum yield of $72 \%$ was attained in 1:4 SPSO-to-ethanol ratio. The lowest yield (16\%) was attained in 1:10 and 1:12 molar ratios. For coconut biodiesel, maximum yield (70\%) was also obtained in 1:4 CCO-to-ethanol ratio. At 1:12 molar ratio, the lowest yield of 14\% was recorded. Therefore, oil-to-ethanol molar ratio was a critical factor in biodiesel yield. The graph was plotted in Microsoft Excel version 365 Pro Plus. Experiments were performed in duplicate 


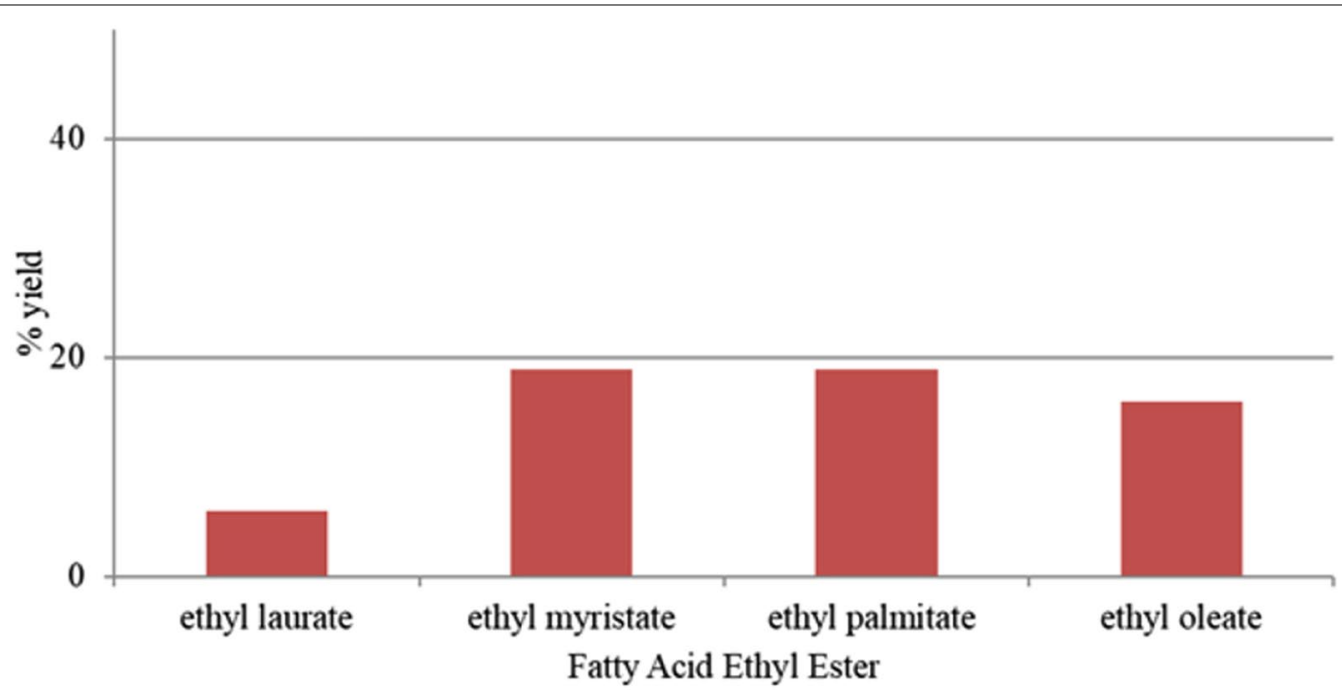

Fig. 2 Percent yield of fatty acid ethyl esters at 1:4 SPSO-to-ethanol molar ratio. Salvadora biodiesel obtained from the most productive SPSO-to-ethanol molar ratio (1:4) was analyzed through gas chromatography to find out the composition of major ethyl esters in the biodiesel yield. Ethyl laurate was found in the lowest quantity (6\%) followed by the highest percentages of ethyl myristate and ethyl palmitate (19\% each). The quantity of ethyl oleate ranged up to 16\%. Therefore, mostly esters of medium- and long-chain fatty acids were found in Salvadora biodiesel at 1:4 molar ratio. The graph was plotted in Microsoft Excel version 365 Pro Plus. Experiments were performed in duplicate

CCO-to-ethanol molar ratio) that the percent yield of the esters was mainly of medium-chain fatty acids viz. ethyl caprate, ethyl laurate, and ethyl myristate (Fig. 3). Therefore, coconut biodiesel consisted mainly of the esters of medium-chain fatty acids.

\section{A comparison of estimated biodiesel properties with standard}

Table 2 gives the estimated fuel properties of Salvadora biodiesel and coconut biodiesel and their comparison with the ASTM standard for biodiesel. Salvadora

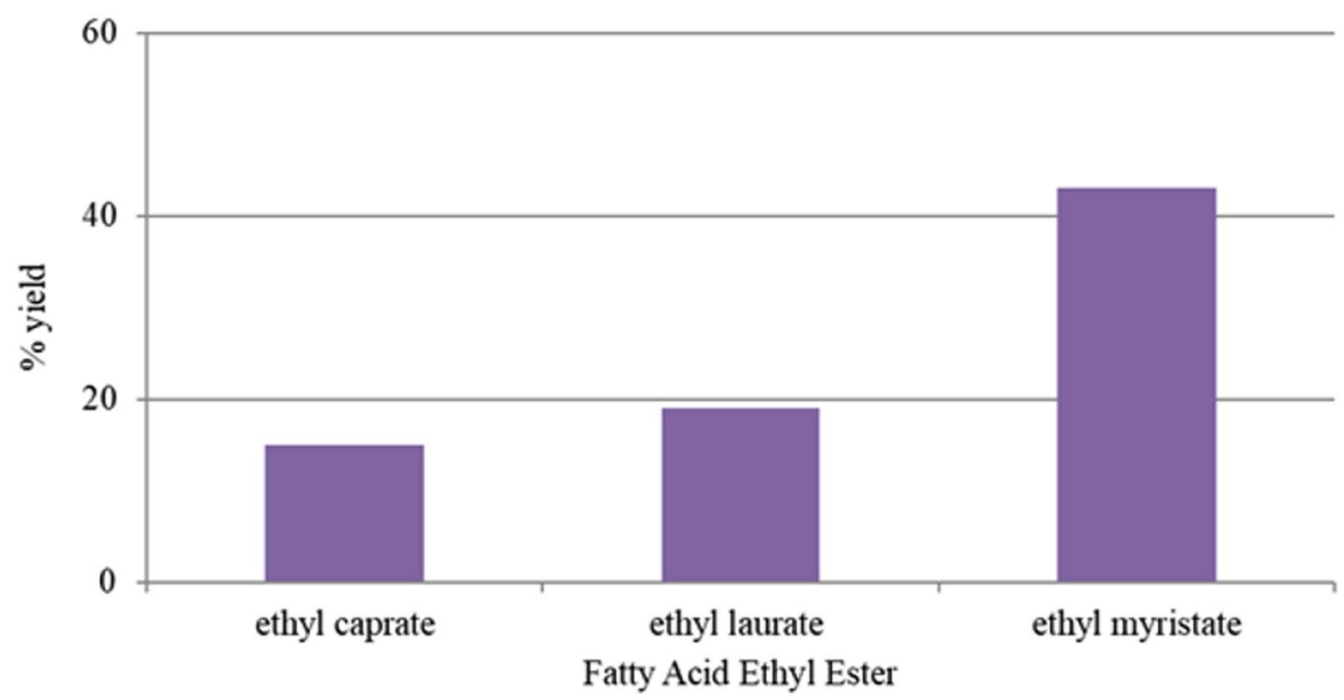

Fig. 3 Percent yield of fatty acid ethyl esters at 1:4 CCO-to-ethanol molar ratio. Coconut biodiesel obtained from the most productive CCO-to-ethanol molar ratio (1:4) was analyzed through gas chromatography to determine the composition of major ethyl esters in biodiesel. Mainly esters of medium-chain fatty acids incorporated the coconut biodiesel produced at this ratio which included ethyl caprate (15\%), ethyl laurate (19\%), and ethyl myristate (43\%). The graph was plotted in Microsoft Excel version 365 Pro Plus. Experiments were performed in duplicate 
Table 2 Estimated fuel properties of Salvadora biodiesel and coconut biodiesel and comparison with standard

\begin{tabular}{|c|c|c|c|}
\hline Property & Salvadora biodiesel & Coconut biodiesel & ASTM D6751 standard \\
\hline SFA: saturated fatty acid (\%) & 82.93 & 87.78 & - \\
\hline MUFA: monounsaturated fatty acid (\%) & 13.69 & 7.43 & - \\
\hline PUFA: polyunsaturated fatty acid (\%) & 0.0 & 0.86 & - \\
\hline DU: degree of unsaturation & 13.69 & 9.15 & - \\
\hline SV: saponification value (mg/g) & 228.29 & 257.71 & - \\
\hline IV: iodine value & 11.97 & 8.23 & - \\
\hline CN: cetane number & 67.51 & 65.62 & Minimum 47 \\
\hline LCSF: long-chain saturated factor & 4.81 & 1.30 & - \\
\hline CFPP: cold filter plugging point $\left({ }^{\circ} \mathrm{C}\right)$ & -1.35 & -12.37 & - \\
\hline CP: cloud point $\left({ }^{\circ} \mathrm{C}\right)$ & 9.51 & 0.61 & Report \\
\hline PP: pour point $\left({ }^{\circ} \mathrm{C}\right)$ & 3.50 & -6.15 & -15 to 10 \\
\hline APE: allylic position equivalent & 9.54 & 9.15 & - \\
\hline BAPE: bis-allylic position equivalent & 1.14 & 1.34 & - \\
\hline OS: oxidation stability (h) & Infinity & 139.71 & Minimum 3 \\
\hline HHV: higher heating value & 37.28 & 36.09 & Report \\
\hline U: kinematic viscosity $\left(\mathrm{mm}^{2} / \mathrm{s}\right)$ & 3.00 & 2.25 & $1.9-6.0$ \\
\hline$\rho:$ density $\left(\mathrm{kg} / \mathrm{m}^{3}\right)$ & 839 & 837 & $850-900$ \\
\hline
\end{tabular}

The fuel properties of Salvadora biodiesel and coconut biodiesel were estimated using BiodieselAnalyzer@ Version 2.2. A total of 17 properties ranging from saturated fatty acid (SFA) to density (in $\mathrm{kg} / \mathrm{m}^{3}$ ) were estimated by the software. These properties were based on the fatty acid profiles of the parent vegetable oils, i.e., SPSO and CCO. The data are shown in different values according to the property. These properties were then compared with ASTM D6751 standard of biodiesel. Salvadora biodiesel meets requirements such as cetane number, kinematic viscosity, cloud point, and pour point while its density is very close to the limit. Coconut biodiesel produced in this study meets requirements such as cetane number, kinematic viscosity, cloud point, pour point, and oxidation stability while its density is also very close to the limit; - means that the property does not have a specified limit

biodiesel produced in the present study meets the international requirements such as cetane number, kinematic viscosity, cloud point, and pour point while its density is very close to the specified limit. Coconut biodiesel produced also meets requirements such as cetane number, kinematic viscosity, cloud point, pour point, and oxidation stability while its density is also very close to the specified limit.

\section{Discussion}

Both SPSO and CCO are good candidates for producing medium-chain biodiesel by enzymatic transesterification with the use of ethanol as acyl acceptor in a greener and eco-friendly way. Saturated mediumchain fatty acids ranging from lauric acid and myristic acid are found in high quantity in SPSO. The fatty acid composition of SPSO also nearly confirms to that reported in literature (Mariod et al. 2009). In contrast, edible vegetable oils such as soybean and sunflower oils comprising long-chain fatty acids were used in previous studies on production of biodiesel. Other researchers determined fatty acid composition of Cinnamomum camphora (camphor tree) seed oil which consisted mainly of saturated medium-chain fatty acids ranging from capric acid (53.4\%) and lauric acid (38.7\%). The oil was used for enzymatic transesterification with immobilized lipase from Candida sp. 99-125 (Liu et al.
2014). Like camphor tree seed oil, SPSO is non-edible which gives it an advantage over edible vegetable oils which are used for food purposes. Further, the plant species (Salvadora persica) has the potential of an oilseed crop for producing biodiesel fuel on a large scale. As compared to SPSO, Salvadora persica root oil was not found applicable for producing medium-chain biodiesel as it contains long-chain fatty acids in high quantity.

The other feedstock used, i.e., CCO is also non-edible. Besides containing lauric and myristic acid in high quantity, it also consists of caprylic acid and capric acid which are other saturated medium-chain fatty acids. Suryanto et al. (2015) obtained lauric acid (41.21\%) and myristic acid $(23.90 \%)$ as the dominant fatty acids in coconut oil. Caprylic and capric acid were the other medium-chain fatty acids that were detected. The coconut oil was used for transesterification using $\mathrm{KOH}$ (chemical) catalyst and microwave as energy source. The fatty acid composition of CCO used in this study also nearly agrees with that of Rossell et al. (1985).

The average molecular weight of oil feedstock used for biodiesel production, i.e., SPSO and CCO is in close range of what researchers found for other vegetable oils having high quantity of medium-chain fatty acids. Oliveira et al. (2014) reported that the average molecular weight of babassu oil is $709.90 \mathrm{~g} / \mathrm{mol}$. Liu et al. (2014) 
also found that the average molecular weight of camphor tree seed oil is $600 \mathrm{~g} / \mathrm{mol}$.

TLC is a less expensive procedure which needs low equipment and operation costs (Fontana et al. 2009) and which can qualitatively confirm the conversion of triglycerides in oil into alkyl esters present in biodiesel. Further, it gives reasonably accurate indication of oil and ethyl ester content present in the mixture (Babajide et al. 2010). In this study, TLC indicated fatty acid ethyl esters produced in different batches. Except for the lane of Salvadora biodiesel from 1:4 SPSO-to-ethanol ratio, similar patches were observed which means that esters were present in these samples. The exception could be due to inappropriate handling. Lighter patches were obtained in all the lanes of coconut biodiesel which also indicated ethyl esters.

An important and crucial parameter in transesterification is oil-to-alcohol molar ratio. Since 1:3 ratio is just adequate for the theoretical reaction, higher molar ratios have been used by researchers to maximize biodiesel production (Ramadhas et al. 2005). In case of SPSO and CCO, 1:4 oil-to-ethanol ratio can be considered the optimum for maximum conversion into ethyl esters. The reason for decrement of biodiesel yield at higher ratios may be due to inhibition of lipase by ethanol. The lipase may lose its stability in higher concentrations of ethanol leading to lower yields. Other researchers attained highest yields of biodiesel at around similar ratios while experimenting transesterification of oils rich in medium-chain fatty acids and this study also agrees with their findings (Liu et al. 2014; Oliveira et al. 2014).

Burkholderia cepacia lipase is a capable biocatalyst for production of biodiesel from SPSO and CCO provided the right conditions which includes optimum oil-to-ethanol molar ratio. In the current study, the focus was primarily to explore the local feedstock oil as potential source for biodiesel. The use of free enzyme for transesterification of these oils was to establish the procedure and look for products obtained. Indeed, use of immobilized lipase might have made the process more economical but it has its own limitations particularly when using in reactions involving solvents. There are disagreements about immobilization techniques and the support material used. This makes an interesting future research prospect to use immobilized lipase for the said process.

Burkholderia cepacia lipase is also known formerly as Pseudomonas cepacia lipase (Sánchez et al. 2018). The active site of Pseudomonas cepacia and Candida lipase is like funnel (Pleiss et al. 1998) with active triad made up of Asp-His-Ser acting as a charge-relay system (Bommarius and Riebel-Bommarius 2004). The side chain of Asp carboxyl group is hydrogen bonded to His where it forms hydrogen bond with $\mathrm{OH}$ group of Ser. The mechanism is that His pulls the proton from $\mathrm{OH}$ of Ser forming oxyanion ion that in turns form tetrahedral intermediate with substrate that results in the formation of diglyceride (Al-Zuhair 2007). The serine ester formed reacts with alcohol to complete the transesterification. The histidine nitrogen removes hydrogen from the alcohol molecule forming the alkyl oxide anion. The hydroxide attacks the carbonyl carbon, the intermediate oxyanion is stabilized by a hydrogen bond (tetrahedral intermediate 2), the electrons are pushed back to the carbonyl carbon, and the free fatty acid is formed. The serine oxygen then reclaims the hydrogen situated on the histidine to re-establish the hydrogenbonding network. The aspartic acid serves as to pull positive charge from the histidine during the times it is fully protonated.

The feedstocks, i.e., SPSO and CCO were used without any pre-treatment. This is an advantage of enzymatic transesterification which reduces the overall costs. In contrast, chemical transesterification needs pre-treatment of oil feedstock which is a necessity to reduce free fatty acids content. Otherwise, the free fatty acids will produce an intermediate compound namely soap which can inhibit the transesterification reaction. Enzymes are insensitive to free fatty acids in the oil (Sebastian et al. 2016) as they catalyze reactions of both triglycerides and free fatty acids to produce esters (Guldhe et al. 2016).

We propose here that both SPSO and CCO are emerging feedstock oils for producing biodiesel based on the comparison with international standard. An example is the American standard ASTM D6751 which is applicable for both fatty acid methyl esters and fatty acid ethyl esters (Barabás and Todoruț 2011). The properties of biodiesel depend directly on the fatty acid composition of the parent oil which allows the prediction of properties of a biodiesel sample. Examples of the parameters of interest are cetane number, kinematic viscosity, the cold flow properties, and the oxidation stability (Talebi et al. 2014).

Solvent-free system is better as it is economical, safe, and environment friendly. It is equally as useful as the process being carried out in the presence of solvent (Dossat et al. 2002). This obviates the need of adding expensive and toxic solvents such as $n$-hexane and petroleum ether. In solvent-free system, the incomplete hydrolysis resulted in low levels of glycerol that reduces the hindrance in ongoing process of transesterification (Marty et al. 1997). Other researchers have used these solvents when carrying out transesterification of vegetable oils with methanol to reduce the negative effect of the acyl acceptor on lipase (Soumanou and Bornscheuer 2003; Lara and Park 2004). Since ethanol was used in this study, no additional solvent was required in the reaction 
mixture. This makes the process safer and eco-friendly at low cost of production. Therefore, we propose here that SPSO and CCO should be checked for their use as fuel and if it is proven machine friendly, should be produced on large scale.

\section{Conclusion}

Biodiesel production from SPSO and CCO using Burkholderia cepacia lipase as biocatalyst in a solvent-free system was investigated in this study. It paves the way for a green route for biodiesel production on a large scale. This work is a step in the right direction to promote the use of non-edible vegetable oils over edible ones to produce biodiesel. Further, it would lead to more usage of lipases as biocatalysts in biodiesel production as compared to chemical catalysts. Ethanol, which can also be produced from biomass fermentation, can be used as acyl acceptor in transesterification reaction to produce biodiesel and this makes the process eco-friendly. This study concluded that Burkholderia cepacia lipase is a good choice for successfully getting high yields of biodiesel from SPSO and $\mathrm{CCO}$ at low oil-to-ethanol molar ratios.

\section{Abbreviations \\ SPSO: Salvadora persica seed oil; CCO: Crude coconut oil; TLC: thin layer chromatography.}

\section{Acknowledgements}

The authors are thankful to the Chairperson, Department of Biochemistry, University of Karachi for providing working lab in the department.

\section{Authors' contributions}

Experiments were performed by AAAB and MNS. AM and TH participated in writing the manuscript. All authors read and approved the final manuscript.

\section{Funding}

There was no major funding source for the project. The study was partially funded by the author himself, University of Karachi, and Virtual University of Pakistan.

\section{Availability of data and materials}

The data set (table and graphs) supporting this article's conclusion is available.

Ethics approval and consent to participate

Not applicable.

\section{Consent for publication}

Not applicable.

\section{Competing interests}

The authors declare that they have no competing interests.

\author{
Author details \\ ${ }^{1}$ Department of Molecular Biology, Faculty of Science and Technology, Virtual \\ University of Pakistan, Lahore, Pakistan. ${ }^{2}$ Department of Biochemistry, Univer- \\ sity of Karachi, Karachi, Pakistan.
}

Received: 15 June 2019 Accepted: 9 October 2019

Published online: 23 October 2019

\section{References}

Abdulla R, Ravindra P (2013) Immobilized Burkholderia cepacia lipase for biodiesel production from crude Jatropha curcas L. oil. Biomass Bioenergy 56:8-13. https://doi.org/10.1016/j.biombioe.2013.04.010

Al-Zuhair S (2007) Production of biodiesel: possibilities and challenges. Biofuel Bioprod Biorefin 1:57-66. https://doi.org/10.1002/bbb.2

Atabani AE, Silitonga AS, Badruddin IA, Mahlia TMI, Masjuki HH, Mekhilef S (2012) A comprehensive review on biodiesel as an alternative energy resource and its characteristics. Renew Sust Energy Rev 16:2070-2093. https://doi. org/10.1016/j.rser.2012.01.003

Babajide O, Petrik L, Musyoka N, Amigun B, Ameer F (2010) Use of coal fly ash as a catalyst in the production of biodiesel. Pet Coal 52:261-272

Barabás I, Todoruț IA (2011) Biodiesel quality, standards and properties. In: Montero G (ed) Biodiesel: quality, emissions and by-products. InTech, Rijeka

Bommarius AS, Riebel-Bommarius BR (2004) Biocatalysis: fundamentals and applications. Wiley-VCH, Weinheim

Bureau C (2007) The CRB commodity yearbook 2006 with CD-ROM. Wiley, Hoboken

Carvalho AK, da Conceição LR, Silva JP, Perez VH, de Castro HF (2017) Biodiesel production from Mucor circinelloides using ethanol and heteropolyacid in one and two-step transesterification. Fuel 202:503-511. https://doi. org/10.1016/j.fuel.2017.04.063

Chen YH, Chen JH, Luo YM (2012) Complementary biodiesel combination from tung and medium-chain fatty acid oils. Renew Energ 44:305-310. https:// doi.org/10.1016/j.renene.2012.01.098

Dossat V, Combes D, Marty A (2002) Lipase-catalysed transesterification of high oleic sunflower oil. Enzyme Microb Technol 30:90-94. https://doi. org/10.1016/s0141-0229(01)00453-7

Fontana JD, Zagonel G, Vechiatto WW, Costa BJ, Laurindo JC, Fontana R, Pelisson L, Jorge BH, Lanças FM (2009) Simple TLC-screening of acylglycerol levels in biodiesel as an alternative to GC determination. J Chromatogr Sci 47:844-846. https://doi.org/10.1093/chromsci/47.9.844

Guldhe A, Singh P, Kumari S, Rawat I, Permaul K, Bux F (2016) Biodiesel synthesis from microalgae using immobilized Aspergillus niger whole cell lipase biocatalyst. Renew Energy 85:1002-1010. https://doi.org/10.1016/j.renen e.2015.07.059

Gunstone FD, Harwood JL, Dijkstra AJ (2007) The lipid handbook with CD-ROM. CRC Press, Boca Raton

Jegannathan KR, Jun-Yee L, Chan ES, Ravindra P (2010) Production of biodiesel from palm oil using liquid core lipase encapsulated in $\mathrm{K}$-carrageenan. Fuel 89:2272-2277. https://doi.org/10.1016/j.fuel.2010.03.016

Khan MA, Qaiser M (2006) Halophytes of Pakistan: characteristics, distribution and potential economic usages. In: Khan MA, Böer B, Kust GS, Barth HJ (eds) Sabkha ecosystems volume II: West and Central Asia. Springer, Netherlands, Dordrecht

Kumar S, Rani C, Mangal M (2012) A Critical review on Salvadora persica: an important medicinal plant of arid zone. Int J Phytomedicine 4:292-303

Lara PV, Park EY (2004) Potential application of waste activated bleaching earth on the production of fatty acid alkyl esters using Candida cylindracea lipase in organic solvent system. Enzyme Microb Tech 34:270-277. https://doi. org/10.1016/j.enzmictec.2003.10.015

Liu J, Deng L, Wang M, Nie K, Liu L, Tan T, Wang F (2014) Lipase catalyzed synthesis of medium-chain biodiesel from cinnamonum camphora seed oil. Chinese J Chem Eng 22:1215-1219. https://doi.org/10.1016/j.cjche.2014.09.033

Marina AM, Che Man YB, Amin I (2009) Virgin coconut oil: emerging functional food oil. Trends Food Sci Tech 20:481-487. https://doi.org/10.1016/j. tifs.2009.06.003

Mariod AA, Matthäus B, Hussein IH (2009) Chemical characterization of the seed and antioxidant activity of various parts of Salvadora persica. J Am Oil Chem Soc 86:857-865. https://doi.org/10.1007/s11746-009-1422-3

Marty A, Dossat V, Condoret JS (1997) Continuous operation of lipase-catalyzed reactions in nonaqueous solvents: influence of the production of hydrophilic compounds. Biotechnol Bioeng 56:232-237. https://doi.org/10.1002/ (sici)1097-0290(19971020)56:2\%3c232:aid-bit12\%3e3.0.co;2-i

Oliveira MVS, Da Rós PCM, Mattedi S, Castro HF, Soares CMF, Lima ÁS (2014) Transesterification of babassu oil catalyzed by Burkholderia cepacia encapsulated in sol-gel matrix employing protic ionic liquid as an additive. Acta Sci Technol 36:445-451. https://doi.org/10.4025/actascitechnol.v36i3.19871 
Pham L (2016) Coconut (Cocos nucifera). In: McKeon TA, Hayes DG, Hildebrand DF, Weselake RJ (eds) Industrial oil crops. AOCS Press, Urbana

Pleiss J, Fischer M, Schmid RD (1998) Anatomy of lipase binding sites: the scissile fatty acid binding site. Chem Phys Lipids 93:67-80. https://doi.org/10.1016/ s0009-3084(98)00030-9

Rahman HIH (2000) The chemistry of coconut oil. Bruneiana: Anthology of Science Articles 1:9-15

Ramadhas AS, Jayaraj S, Muraleedharan C (2005) Biodiesel production from high FFA rubber seed oil. Fuel 84:335-340. https://doi.org/10.1016/j. fuel.2004.09.016

Reddy MP, Shah MT, Patolia JS (2008) Salvadora persica, a potential species for industrial oil production in semiarid saline and alkali soils. Ind Crops Prod 28:273-278. https://doi.org/10.1016/j.indcrop.2008.03.001

Rossell JB, King B, Downes MJ (1985) Composition of oil. J Am Oil Chem Soc 62:221-230. https://doi.org/10.1007/BF02541382

Saifuddin N, Fazilii AS, Kumaran P, Pei-Jua N, Priathashini P (2016) The production of biodiesel and bio-kerosene from coconut oil using microwave assisted reaction. IOP Conf Ser Earth Environ Sci 32:012039. https://doi. org/10.1088/1755-1315/32/1/012039

Sánchez DA, Tonetto GM, Ferreira ML (2018) Burkholderia cepacia lipase: a versatile catalyst in synthesis reactions. Biotechnol Bioeng 115:6-24. https://doi. org/10.1002/bit.26458

Sebastian J, Muraleedharan C, Santhiagu A (2016) A comparative study between chemical and enzymatic transesterification of high free fatty acid contained rubber seed oil for biodiesel production. Cogent Eng 3:1178370. https://doi. org/10.1080/23311916.2016.1178370

Shahidi F (ed) (2006) Nutraceutical and specialty lipids and their co-products. CRC Taylor \& Francis, Boca Raton

Sharma A, Kar SK (eds) (2015) Energy sustainability through green energy. Springer, India
Shrestha D, Gerpen JV (2010) Biodiesel from oilseed crops. In: Singh BP (ed) Industrial crops and uses. CABI, Wallingford

Soumanou MM, Bornscheuer UT (2003) Improvement in lipase-catalyzed synthesis of fatty acid methyl esters from sunflower oil. Enzyme Microb Technol 33:97-103. https://doi.org/10.1016/S0141-0229(03)00090-5

Souza LTA, Mendes AA, Castro HFD (2016) Selection of lipases for the synthesis of biodiesel from jatropha oil and the potential of microwave irradiation to enhance the reaction rate. Biomed Res Int. https://doi. org/10.1155/2016/1404567

Suryanto A, Suprapto S, Mahfud M (2015) The production of biofuels from coconut oil using microwave. Mod Appl Sci 9:93-98. https://doi.org/10.5539/ mas.v9n7p93

Talebi AF, Tabatabaei M, Chisti Y (2014) BiodieselAnalyzer: a user-friendly software for predicting the properties of prospective biodiesel. Biofuel Res J 1:55-57. https://doi.org/10.18331/brj2015.1.2.4

Talebian-Kiakalaieh A, Amin NAS, Mazaheri H (2013) A review on novel processes of biodiesel production from waste cooking oil. Appl Energy 104:683-710. https://doi.org/10.1016/j.apenergy.2012.11.061

\section{Publisher's Note}

Springer Nature remains neutral with regard to jurisdictional claims in published maps and institutional affiliations. 